\title{
Structural Patternings of English and Armenian Compounds
}

\author{
A. Hovhannisyan ${ }^{1}$, G. Barseghyan ${ }^{2}$
}

${ }^{1}$ Shirak State University, ${ }^{2}$ Yerevan State University

Paper received 08.05.21; Accepted for publication 26.05.21.

\section{https://doi.org/10.31174/SEND-HS2021-253IX45-06}

\begin{abstract}
The current research is primarily devoted to outlining word-formation trends in compounds. Despite many efforts made by various linguists, word-formation still remains an uncharted area. The merit of this article lies in detailed exposition of some important problems connected with compounding in English and Armenian. Based on a contrastive approach, the main focus of the discussion will be to show both allomorphic and isomorphic features of typologically different languages in patterning compounds.

Keywords: contrastive study, compounding, structuring of compounds, full equivalence, partial equivalence, no equivalence, etc.
\end{abstract}

Before embarking upon a detailed exposition of noun + noun compounds in contrastive languages it is helpful to have a general overview of compounding as word formation means in English. L. Jefferies (2006) distinguishes three different processes of word-formation means in English: inflection, derivation and compounding. In the words of Jefferies the inflection is the process by which the main lexical word classes (noun, verb, adjective and adverb) in English acquire regular ending to form particular grammatical structure (Jefferies:77). Derived forms normally have a morpheme added to the base form and change the word class of the original. It can be inferred from the above that in case of inflection the added morphemes to the base of the word alter simply the grammatical form in ways that are relevant to the word class concerned. Whilst, derivation results in a relevant change in a word meaning.

It becomes clear that the above treatment of derivation and inflection is purely morphemic. The demarcation line that is carved between these two word-formation means is relevant to the function of morpheme; whether it operates as a derivation (lexical) marker, or non-derivational (grammatical)marker. Obviously, there are some good seeds of reasoning in the author's statement. Grammar and lexicology often make use of the same technique. A close connection between these aspects of language is conditioned by the manifold and inseparable ties between the objects of their study. Therefore morphemes alongside with their lexical meaning possess grammatical meaning. This scheme (classification), however, failed to show the essence of word-formation means as in this case morphemic analysis of words and structural word-formation analysis are treated as equal processes. Morphemic analysis establishes only the ultimate constituents that make up the word, whilst a structural word-formation analysis studies the structural patterns or rules on which words are built. Though in some cases they coincide (Arnold:34). The main drawback of Jefferies's approach is that functional morphemes are treated as lexical (derivational) markers. Arnold's suggestion is a radical departure from the earlier view of word-formation. Only derivational affixes (morphemes) can construct words embracing different lexical meanings (Arnold,1973:30). In the remaining part of the study we shall hold this view.

Tackling compounding, it should be noted that Jefferies's approach to carving compounds is also morphemic. In terms of morphemes compounding is the combining of two free morphemes into a single word.

The definition of compounds is unproblematic but it will suffice for present purposes to illustrate Arnold's understandings: "Compound words are words consisting at least two stems which occur in the language as free forms" (Arnold, 1973:60). In a compound word the immediate constituents obtain integrity and structural cohesion that make them function in a sentence as a separate lexical unit (Arnold, 1973:60).

The structural cohesion implies three types of relations, namely the relations of the members to each other, the relations of the whole to the members, and correlation with equivalent free phrases (Arnold, 1973:60). The combining of two free morphemes into a single word is not very different from making a phrase out of two words, through these some important distinctions. What gives compounds their status as individual lexemes is precisely this obscurity in the meaning; the meaning of the compound is not simply the sum of its parts. The identity as an individual lexical item is emphasized by their phonological shape, which carries a single main stress unlike the equivalent phrase, which carries two word stresses(Jefferies: 82).

A brief account of compounding as word formation means must suffice for the present study. At the further stage we are very much engaged in an in-depth analysis of translation strategies adopted for each English compound in Armenian, focusing more specifically on translations in the target language with the aim of sketching some possible contrasts between English compounding and its counterpart in Armenian.

Multi-word expressions are some of the most challenging translation difficulties. Different scholars of linguistics suggest different strategies of translating word combinations. Baker emphasized that "real danger comes in translating literary since the result will usually be nonsense in the receptor language" (Baker, 1984:143). This statement should be taken with caution as in some translations compounds are transferred into the combinations with the same meaning and the same form.

The date obtained showed that contrastive study offers invaluable repertories of translation of compound equivalence. In terms of equivalency are dominant: full equivalence, partial equivalence and no equivalence.

1.Total (or Full)equivalence; translating SL expression with the very similar expression in TL expression in form and meaning means that the TL combination should convey the same meaning and be of an equivalent lexical item. In this case compounds are translated literary calquing the architecture of the given compound as in the below illustrated expressions: landscape-juunzuqun, twen- 
ty-one-puufurtil, railroad-kplumpqho, sunshineupluu2nn, headache - quhuugul, homecomingunnı@inună, in which it constituent of the compound finds its analogical pair in the target language that is relevant both to its composition and meaning.

- It was like a dark and ominous landscape seen by a flash of lightning and in a moment hidden again by the night. (Painted Veil:23)

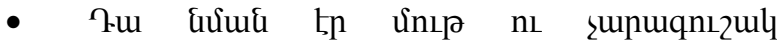

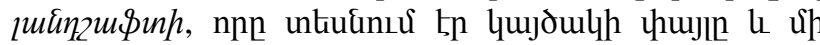

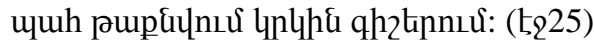

- Her husband, among various physical accomplishments, had been one of the most powerful ends that ever played football at New Haven - a national figure in a way, one of those men who reach such an acute limited excellence at twenty-one that everything afterward savors of anti-climax. (Great Gatsby:15)

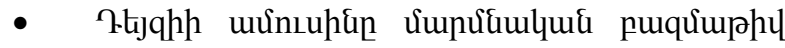

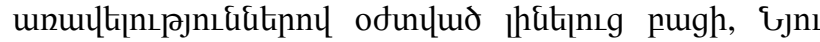

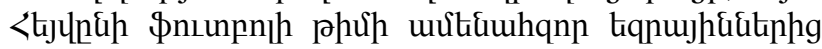

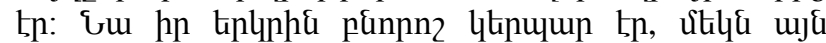

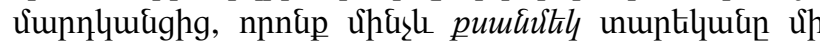

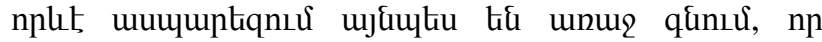

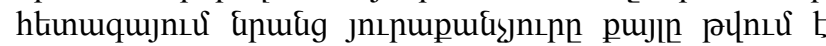
udilnıu: (1652)

- About halfway between West Egg and New York the motor-road hastily joins the railroad and runs beside it for a quarter of a mile, so as to shrink away from a certain desolate area of land.(Great Gatsby:53)

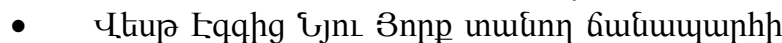

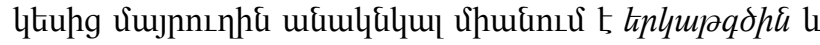

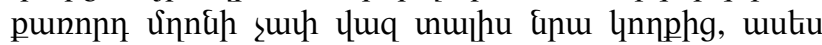

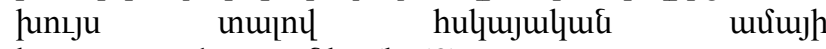
hnпuunupuonıpjnı\&hg:(5,58)

In the frame of this sentence apart from full equivalence (railroad-tpluupqho), we can find paraphrasing in the translation of the noun "halfway", which is transferred in the target language as a free word combinationGuruumuphp lituhg: It's worth pointing out that the nouns (fuuluumuph and liku) constituting the Armenian phrase Guquuuunhh lkuhg take case endings of the genitive (Guluuuuph $\boldsymbol{h}$ ) and ablative (lku $\boldsymbol{h g}$ ) respectively dictated by the grammar rules governing in the language. Typologically, Armenian is classified into the range of agglutinative languages with a highly developed case and conjugation systems.

- I told him. And as I walked on I was lonely no longer. I was a guide, a pathfinder, an original settler. He had casually conferred on me the freedom of the neighborhood. And so with the sunshine and the great bursts of leaves growing on the trees-just as things grow in fast movies-I had that familiar conviction that life was beginning over again with the summer.(Great Gatsby:5)

- furguunpligh: Gl tipp unur uigu, ujlıu

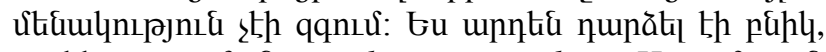

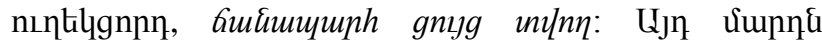

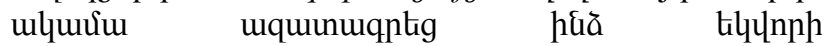

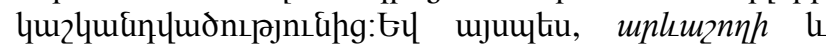

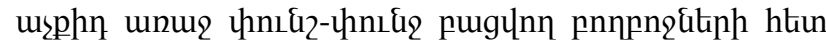

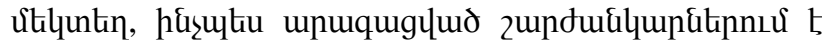

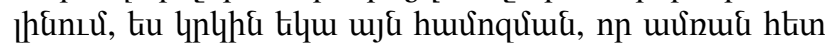

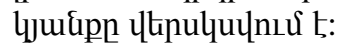

In the above-cited example, on the one hand, the English noun "sunshine" preserves its lineralization in the Armenian translation, and on the other hand, the compound derivative noun "pathfinder" is rendered in mother tongue in the pattern of free multi-word combination

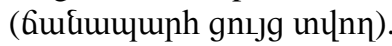

- They insist also on my seeing Mr. Jonestherefore do not be alarmed if you should hear of his having been to me-and, excepting a sore throat and headache, there is not much the matter with me.( Pride and Prejudice:32)

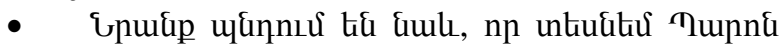

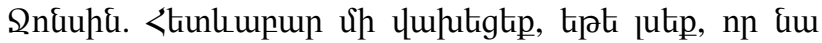

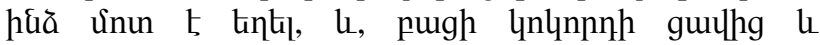

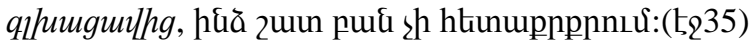

Apparently, the italicized string of Armenian compounds infers the same meaning that is coded in English phrases but with different composition.

The evidence above suggests that in Armenian there are no obvious losses both in plane of content and that of its lineralisation.

2.Partial Equivalence indicates that the wordcombination should be translated with a similar meaning but with the help of paraphrasing. The texture of an interlacing, weaving a compound is carefully crafted by the golden rules of word building means of the given language.

The wording of the given combinations mirrors not only the structural specificity of the give language, but it also reverberates the cognition of that nation.

- At high tide in the afternoon I watched his guests diving from the tower of his raft or taking the sun on the hot sand of his beach while his two motor-boats slit the waters of the Sound, drawing aquaplanes over cataracts of foam. (Great Gatsby:15)

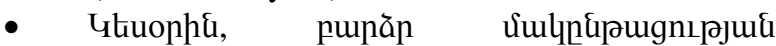

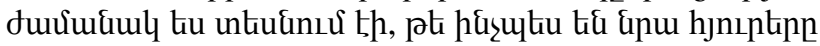

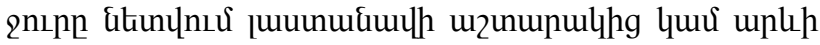

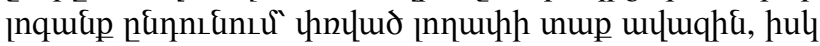

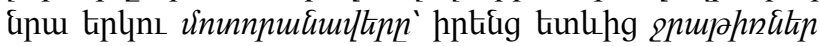
aqtinnl, Gtinpnux tha Uunıanh thphnumtiq uцpufitnp:(5216)

In the adduced sentence, partial equivalence is intertwined with full equivalence (motor-boats is rendered in Armenian as ununnpuiuul).

- $\quad$ She went back to the bedroom and beckoned to him.( Painted Veil 8).

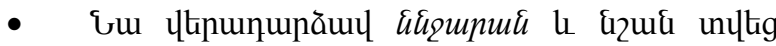
ఓุuut: (159)

- Walter in the courtyard gave directions where this or that was to be placed. (Painted Veil:16)

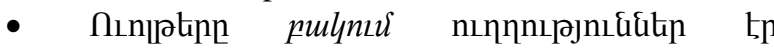

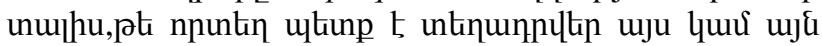
puin: (1,219)

It's noteworthy to mention that compound noun "bedroom" is rendered in Armenian in a simple noun (pul).

- The visit was soon returned in due form. Miss Bennet's pleasing manners grew on the goodwill of Mrs. Hurst and Miss Bingley. (Pride and Prejudice:18)

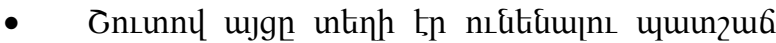

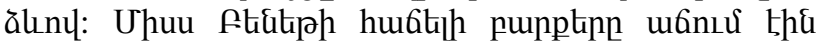

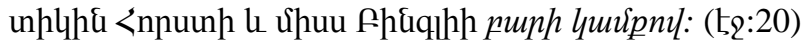


The compound noun "'goodwill'" has transformed into an attributive combination-punh quúpny. In the leftheaded construction puph luuipny ( with a good will) the noun luupp (will) determined by an adjective puph (good) takes an instrumental case ending $(n ц+)$ which is governed by the verb u6kl "grow".

At present, indeed, they were well supplied both with news and happiness by the recent arrival of a militia regiment in the neighborhood; it was to remain the whole winter, and Meryton was the headquarters.( Pride and Prejudice:23)

- Etipluunıúu, hpnp, Enuip jul thu

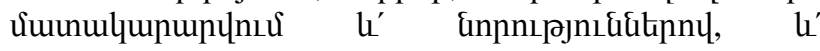

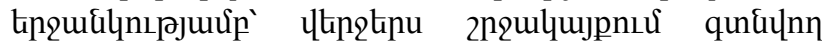

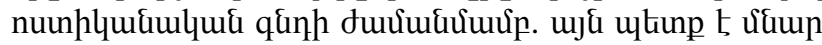

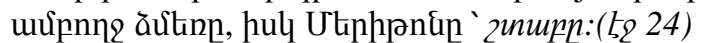

Translation of compound structure into a simple one is intertwined with modulation. Compare headquarters in English and its Armenian equivalent -puly. From linguistic point of view takes place neutralization in the binary opposition singular - plural on which the category of number is erected. The marked member of the opposition (plural form) breaks the border line between the constituents of the opposition and entrudes into the span of singular form referring to one item (thing).

- They insist also on my seeing Mr. Jonestherefore do not be alarmed if you should hear of his having been to me-and, excepting a sore throat and headache, there is not much the matter with me.( Pride and Prejudice:32)

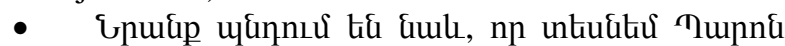

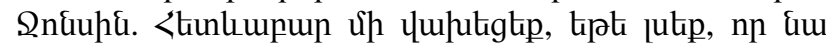

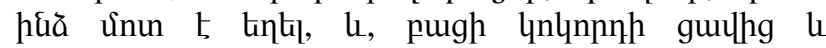

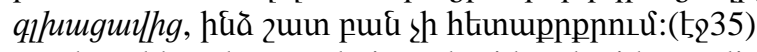

The adduced example is embroidered with two literary translations (headache-qluuuguu, sore throat - lnunnnh guul) and a paraphrase (horsewoman-ăhuulnp lhd ):It is noteworthy that in this sentence synthetic-synthetic rendering (headache-qlhuugul) is combined with analyticalanalytical structuring (sore throat-lynlnpnh gul).

- $\quad$ Elizabeth took up some needlework, and was sufficiently amused in attending to what passed between Darcy and his companion.( Pride and Prejudice:40)

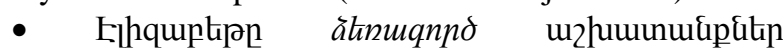

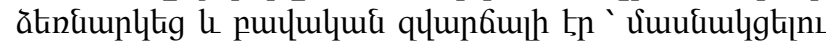

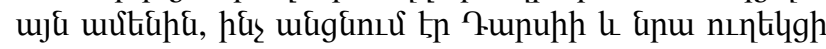
uhqle: (1,242)

- And yet there was something childlike in her still so that your heart went out to her: she seemed to have about her an aroma of the countryside in autumn when the apple trees are laden with fruit and the crops are in and safely housed.(Painted Veil:11)

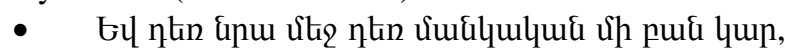

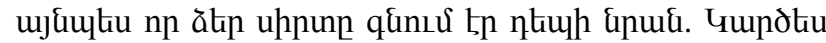

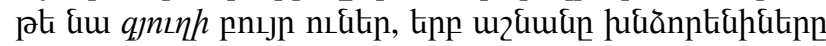

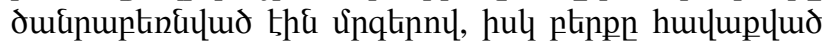

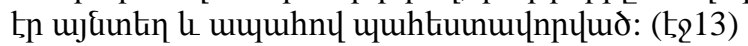

- After sitting a little while with Jane, on Miss Bingley's appearance and invitation, the mother and three daughter all attended her into the breakfast parlour. (Pride and Prejudice:39)

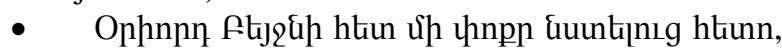

Uhuu fhaqhh unumuphs untuph li hpultiph lnu,

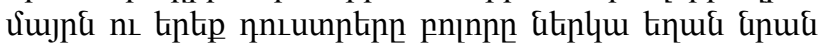
Emhumaim $h$ unuh: (15241)

3.Non-Equivalence leads to another part of investigation. It is recommended that the translator should use the strategy of paraphrasing when encountering such type of combination in Sl have no or zero equivalence in the TL (Baker,1992,p.68). Non-Equivalence charts the panorama of techniques of translation. The variety of techniques like small pieces of glass and stones of different colours pattern a mosaic of translation spectrum.

Using paraphrasing as a this kind of strategy a translator transfers the meaning of a compound either as a single word or a group of words. It's up to the translator to decide how to embraise the compound in the translation. However, this choice can pose many different troubles if the translator is not aware of the linguistic and cultural differences of two languages.

a) A single word: with replicating the same situation as in the original but wording compounds into a simple word. Good examples of "a single word" are furned by the extracted sentences from "Great- Gatsby", "Painted Veil" and their Armenian translations.

- I never saw this great-uncle but I'm supposed to look like him - with special reference to the rather hardboiled painting that hangs in Father's office.( Great Gatsby:8)

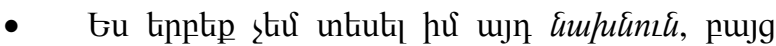

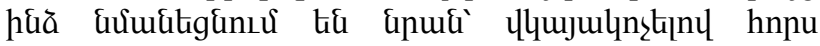

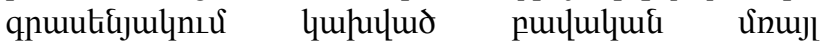

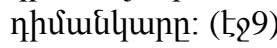

- I was sure he'd start when he saw the newspapers, just as I was sure there'd be a wire from Daisy before noon-but neither a wire nor Mr. Wolfshiem arrived, no one arrived except more police and photographers and newspaper men.( Great Gatsby:40)

- $\quad \mathrm{Gu}$ hưưnquud th, nn Guu qulukin phnpknn

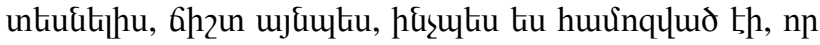

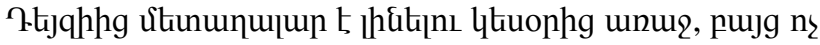

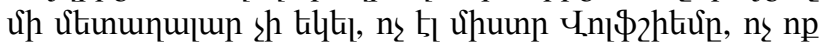

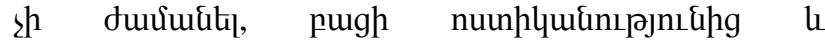

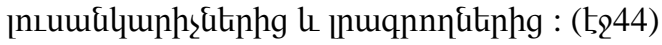

- "No, my dear, you had better go on horseback, because it seems likely to rain; and then you must stay all night." (Pride and Prejudice:30)

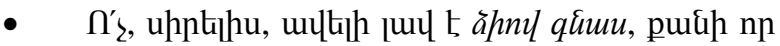

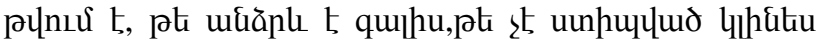

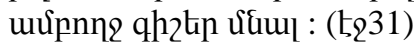

b) Are of equal interest cases with compounds replicating into an affixed (derivational) word.

- Walter was a gentleman, she would do him the justice to acknowledge that, and he loved her; he would do the right thing and allow her to divorce him.(Painted Veil:35)

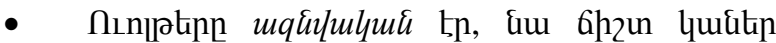

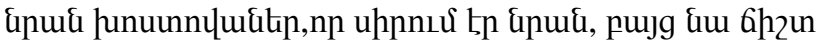

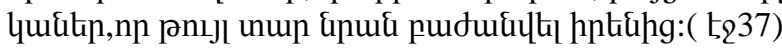

- I believe he's not bad at his job and everyone says he's a good sportsman. (Painted Veil:50)

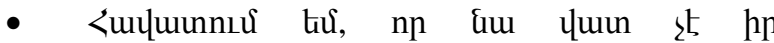

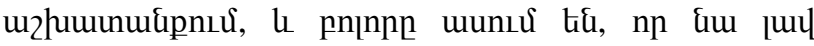
Sunqhl 5: (5251) 
- The handkerchiefs were of very fine lawn and the initials embroidered in a complicated cipher were surmounted by a crown of strawberry leaves. When Kitty had properly admired the workmanship the handkerchiefs were wrapped up again and the parcel handed to her.(Painted Veil:81)

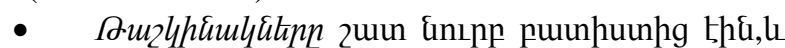

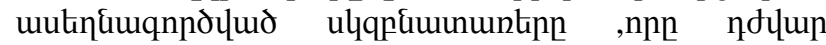

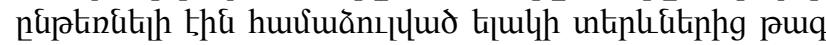

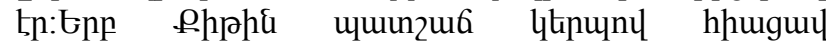

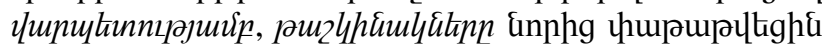

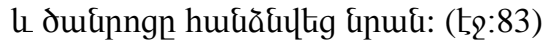

As for the compound derivative "workmanship", this noun is paraphrased into a multi-word combination (üuunzu6 lipuñ).

- Then he went into the jewelry store to buy a pearl necklace or perhaps only a pair of cuff buttons - rid of my provincial squeamishness forever. (Great Gatsby:19)

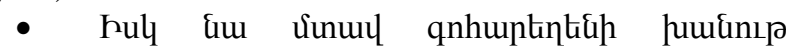

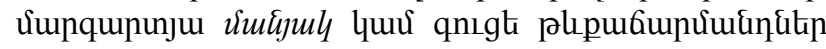

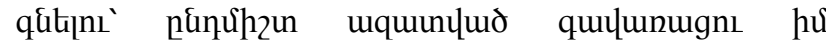
huuhluuquluunnıpjnı\&hg:( 5223 )

- When I went to give up that flat and saw that damn box of dog biscuits sitting there on the sideboard I sat down and cried like a baby.( Great Gatsby:27)

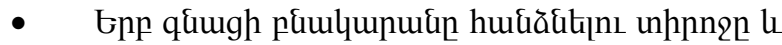

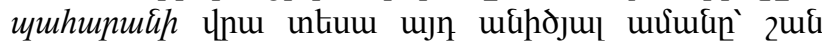

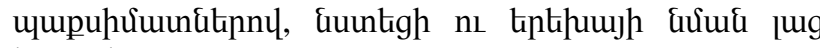
tinu: (1283)

- Mrs. Bennet was prevented replying by the entrance of the footman with a note for Miss Bennet. (Pride and Prejudice:27)

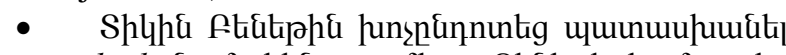

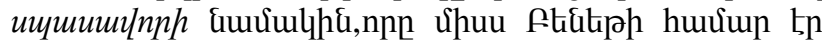

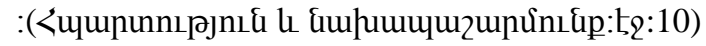

- $\quad$ Elizabeth passed the chief of the night in her sister's room, and in the morning had the pleasure of being able to send a tolerable answer to the inquiries which she very early received from Mr. Bingley by a housemaid, and some time afterwards from the two elegant ladies who waited on his sisters. (Pride and Prejudice:36)

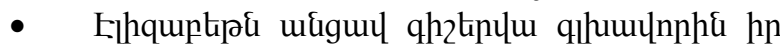

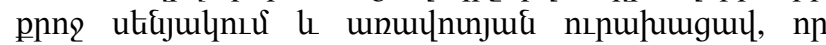

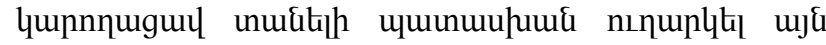

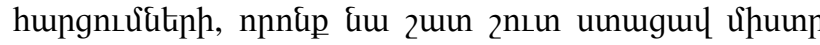

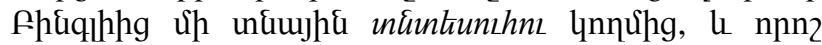

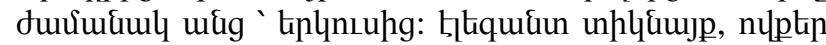
uщuuunıu thd \&nu pnıjnkph: (5237)

5) In some cases, nominal compounds can be transferred into a free combination of words. The italicized nouns exemplify the transformation of compounds into mult-word analytical patterns.

- My own house was an eye-sore, but it was a small eye-sore, and it had been overlooked, so I had a view of the water, a partial view of my neighbor's lawn, and the consoling proximity of millionaires-all for eighty dollars a month.( Great Gatsby13)

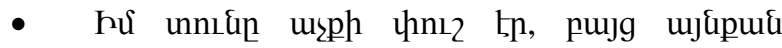

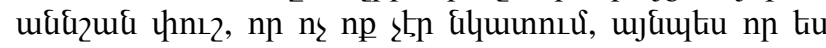

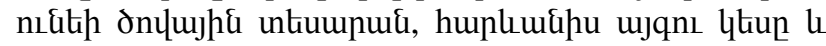

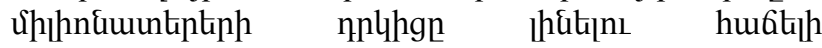

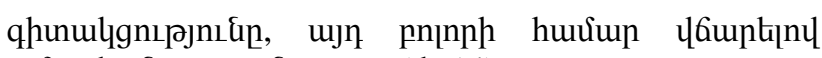
uर्uuuluu nıpunt\& nnjun:( 5214 )

- Kitty sat very still on the sandalwood box and looked with anxious attention at Towns-end. (Painted Veil:32)

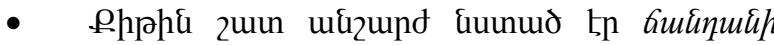

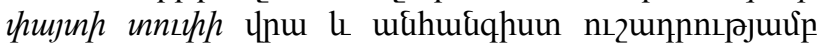

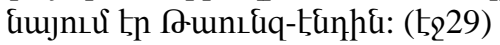

- $\quad$ On the white steps an obscene word, scrawled by some boy with a piece of brick, stood out clearly in the moonlight and I erased it, drawing my shoe raspingly along the stone.(Great Gatsby:19)

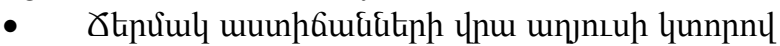

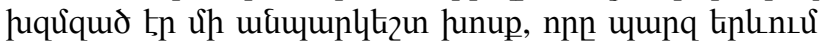

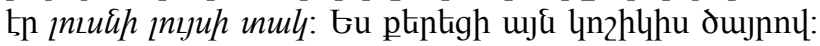
$(5,20)$

- $\quad$ Already it was deep summer on roadhouse roofs and in front of wayside garages, where new red gaspumps sat out in pools of light, and when I reached my estate at West Egg I ran the car under its shed and sat for a while on an abandoned grass roller in the yard.(Great Gatsby:25)

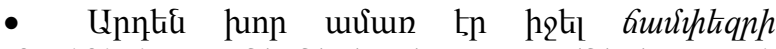

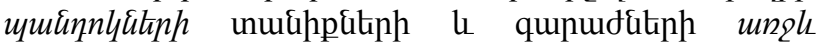

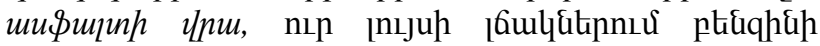

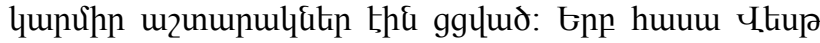

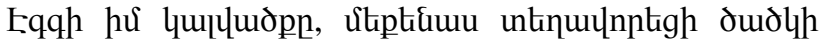

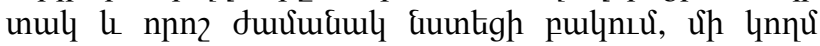

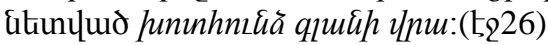

In the last cited example the compounds roadhouse, wayside, gas-pumps are rendered as free combinations, whereas the compound gas-roller is rendered into native language as a synthetic construction implying also partialequivalence.

Passing on to the transformation of structural patternings of compounds we are faced with the interesting fact, that in the process of translation the composition of these expressions either remains the same or take place some changes. Transformations display the way in which the constituents of a compound are combined or rearranged. Are outlined two processes that can produce structural patternings:

a)synthetic compounds are transferred as synthetic ones

- $\quad$ She looked for her handkerchief and knowing what she wanted he gave her bag.(Painted Veil:7)

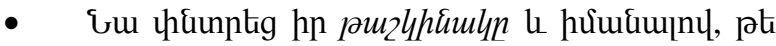

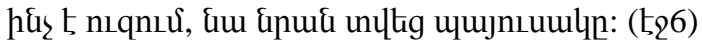

- $\quad$ From a social standpoint the man of science does not exist," he smiled. It was maddening of Charlie to have left it downstairs.(Painted Veil:56)

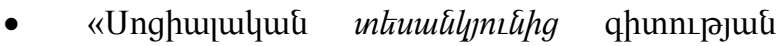

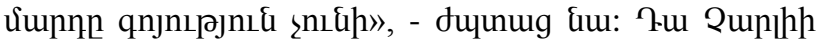

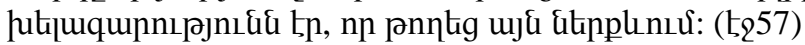

b) an analytical composition is replaced by a synthetic one: the noun dressing table is replaced by hupnuutnuid: In similar vein twenty-one is replicated into puufurtil.

- With a faint gasp of impatience she gave him a shoe horn. She slipped into a kimono and in her bare feet went over to her dressing-table. Her hair was shingled and with a comb she had repaired its disorder before he 
had laced his second shoe. ( Painted Veil:5)

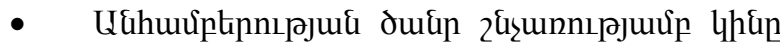

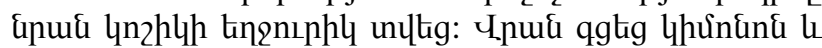

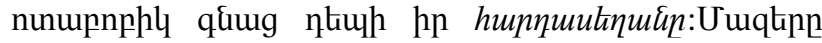

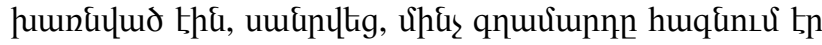
Łnlnnnп lnzhlyn: (15)

- Her husband, among various physical accomplishments, had been one of the most powerful ends that ever played football at New Haven - a national figure in a way, one of those men who reach such an acute limited excellence at twenty-one that everything afterward savors of anti-climax. (Great Gatsby:15)

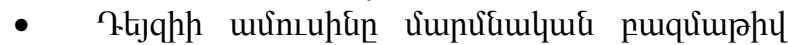

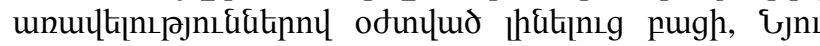

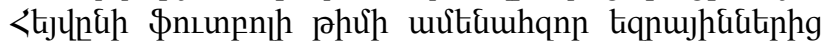

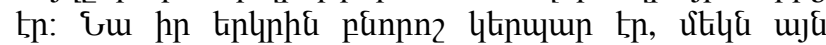

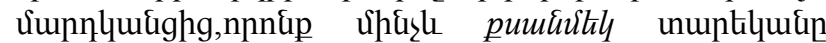

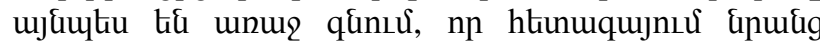

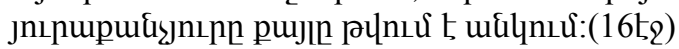

- The Caraways are something of a clan and we have a tradition that we're descended from the Dukes of Buccleuch, but the actual founder of my line was my grandfather's brother who came here in fifty-one, sent a substitute to the Civil War and started the wholesale hardware business that my father carries on today.( Great Gatsby:45)

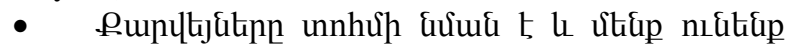

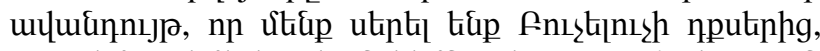

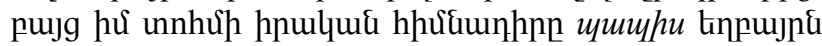

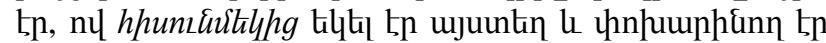

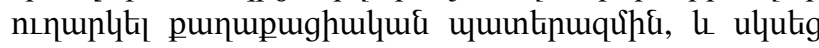

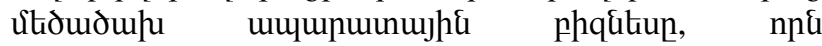
hpulquरumginıu 5 hujpu ujuop: (5247)

In the frame of this sentence, we find an embodiment of different techniques. Firstly, the word fifty-one is trans- lated using a synthetic composition (hpunıfuitil). Secondly, the compound grandfather finds it's relevant equivalent in the native language in the form of simple unitщшищ.

As for the compounds, wholesale and hardware they artfully find their relevants in Armenian.

Thus, the coverage of word formation in contrasted languages is quite wide. One of the most widely used ways to create new words is compounding. The grammatical category of compound word in English and Armenian is always the same as the category of last constituent. In contrasted languages very productive and numerous are compound nouns derived from verbs with postpositives.

The translation of nominal compounds into Armenian embraces a wide spectrum of translation techniques for decoding the encoded message of the author. Specifically compounds may change between spaced, hyphenated and solid (written as a single word) over time and in translations.

The data reveal a clear demarcation between English and Armenian compounds.

The combinations are divided into three categories in terms of equivalence:

- $\quad$ those with total equivalence;

- $\quad$ those with partial equivalence;

- those without equivalence or untranslatable which represent the most difficult area for translators to be rendered into Armenian.

In the set of these procedures, non-equivalent turned, out to be very productive in noun-noun compound translation. There is good reason to assume that equivalence in translation should not be appreciated as search for similarities, since similarities cannot even exist between two target versions of the same text, let alone between the source language, and target language versions.

\section{REFERENCES}

1. Arnold I.The English Word, 2-nd. ed. Moscow, 1973, 303p.

2. Austen Jane, Pride and Prejudice, United Kingdom, 1998, $273 p$

3. Baker, M. In Other Words: A Coursebook on Translation. Routledge. London: 1992, 143p

4. Jefferies L. 2006 Discovering Language, The Structure of Modern English, New York, Palgrave, MacMillan

5. Maugham, W. Somerset, The Painted Veil, United Kingdom $1925,172 p$

6. Scott F. Fitzgerald Great Gatsby, United States 1925, 193p

7. Sutherland The Macmillan,S. Dictionary , Second Edition,
The Macmillan Press LTD 1995 p.57,95,

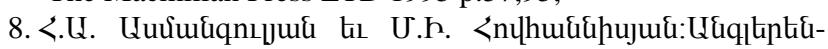

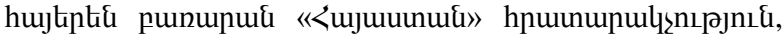
Entıuu, 1984, 1144p.

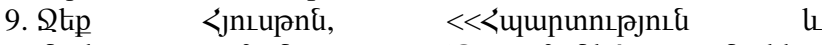

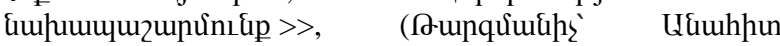
คupujui), 2016,536t,

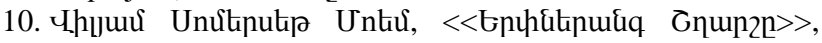

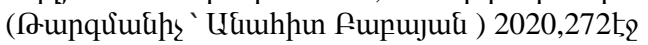

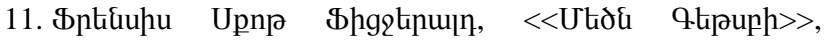

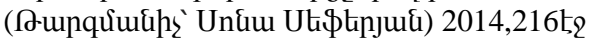

\section{REFERENCES (TRANSLITERATED)}

8. H.A. Asmangulyan yev M.I. Hovhannisyan.Angleren-hayeren barraran «Hayastan» hratarakch'ut'yun, Yerevan, 1984, $1144 \mathrm{p}$.

9. Jek' Hyust'von, <<Hpartut'yun yev nakhapasharmunk' $>>$, (T'argmanich”Anahit Babayan),2016,536ej

10. Vilyam Somerset' Moyem, $<<$ Yerp'nerang Shgharshy $>>$, (T'argmanich' 'Anahit Babayan ) 2020,272ej

11. Frensis Sk'vot' Fits'jerald, <<Metsn Get'sbi $>>$, (T'argmanich' Sona Seferyan) 2014,216ej 